\title{
Estudio de la comunicación de lobby en el caso de la gripe A. Persuasión en la prensa escrita española*
}

\author{
Antonia Perea Rodríguez" \\ Pedro A. Hellín Ortuño***
}

Recibido: 15 noviembre de 2012 - Aprobado: 23 de enero de 2013

\begin{abstract}
Resumen
Presentamos en este artículo los resultados de un análisis cuantitativo sobre el tratamiento informativo por parte de la prensa escrita española en el caso de la gripe A en un periodo de tiempo que va desde abril de 2009 a agosto de 2010, es decir, desde el inicio de la crisis sanitaria cuyas primeras informaciones se originaron en México hasta la finalización de la pandemia declarada por la Organización Mundial de la Salud (OMS).

Se trata de un trabajo retrospectivo donde hemos analizado una muestra de 1.036 unidades de información, que pretende mostrar que el uso masivo de fuentes institucionales en las informaciones entraña el riesgo de ofrecer información que responde a intereses privados y no al interés general.

Asimismo, pretende exponer cuáles fueron los géneros periodísticos más empleados así como la frecuencia en las inserciones de información a lo largo del total de los 17 meses de crisis sanitaria e informativa.

Palabras clave: opinión pública, lobby, H1N1, gripe A, gripe porcina, prensa, gabinetes de prensa, medios de comunicación.
\end{abstract}

* Investigación sobre el "Análisis de la comunicación de la comunicación del lobby farmacéutico en el caso de la gripe A en prensa escrita española", realizada durante el periodo de formación en investigación de la maestranda Toñi Perea, bajo la supervisión del profesor Pedro Hellín. Grupo de investigación Comunicación Corporativa y Sociedad de la Información. Facultad de Comunicación y Documentación de la Universidad de Murcia.

** Licenciada en Periodismo por la Universidad Católica San Antonio de Murcia (fecha), con maestría en Gestión de Información en las Organizaciones en la Universidad de Murcia (fecha). Ha ejercido como periodista en diversos medios de comunicación y gabinetes de comunicación desde el año 2002 hasta la actualidad. Realiza su tesis doctoral en el Programa de Gestión de Información en la Universidad de Murcia y compagina esta tarea con la participación en diversas investigaciones en el ámbito de la comunicación. Email: antonia.perea@um.es.

*** Licenciado en Publicidad y Relaciones Públicas por la Universidad Complutense de Madrid. Especialista en Comunicación Corporativa (U. Complutense de Madrid) y en Técnicas de Análisis Social (U. Alicante), 


\title{
Lobby Communication Study in the Case of Gripe A. Persuasion in Spanish Written Press.
}

\begin{abstract}
This article shows the results of a quantitative analysis on the information treatment by the Spanish written press in the case of Gripe A, from April 2009 to August 2010, that is to say, from the beginning of the sanitary crisis which first information started in Mexico until the ending of pandemic declared by WHO.

It is a retrospective work in which a sample of 1,036 information units have been analyzed. It intends to show that the massive use of institutional sources in information may produce the risk to offer information which responds to private interests rather than to the general interest.

It also intends to report which were the most employed communication media as well as the frequency of information through the seventeen (17) months of information and sanitary crisis.
\end{abstract}

Key words: Public opinion, lobby, H1N1, gripe A, porcine gripe, press, press bureaus, communication media.

Maestría en Sociología (Universidad Complutense de Madrid) y Doctor en Comunicación y Estudios Culturales (U. Sevilla). Visiting scholar en el Theory, Culture and Society Centre (U. Nottinghan Trent) bajo la dirección de Mike Featherstone. Con experiencia como Redactor Creativo y Planner, después pasé a la Universidad Católica San Antonio y de ahí a la Universidad de Murcia, donde soy Profesor Titular y Vicedecano responsable del Grado en Publicidad y Relaciones Públicas. Profesor en cursos de postgrado en las Universidades de Murcia, Sevilla, Málaga, Cádiz, Alicante, Sao Paulo (Brasil), Monterrey (México), Oporto (Portugal) y Saboya (Francia). Autor de "Publicidad y valores posmodernos" (Ed. Siranda, Madrid, 2007), editor de "El discurso publicitario contemporáneo. Su relación con lo social" y otros libros, capítulos y artículos. Siempre en relación con el estudio de las relaciones entre la cultura social y la publicidad. Email: phellin@um.es. 


\section{Introducción}

La investigación desarrollada en este artículo trata en profundidad la crisis sanitaria de la gripe porcina, que recibe otros nombres como AHIN1, o swine flu y que en España recibió el nombre de Gripe A y no de gripe porcina debido a la importancia económica del sector porcino en este país. La misma tuvo su brote de origen en México durante el transcurso del mes de abril de 2009 se desarrolló en todo el mundo y se consideró como pandemia hasta aproximadamente mediados de 2010 cuando se dio por finalizada por parte de la Organización Mundial de la Salud (OMS).

En nuestro caso de estudio la epidemia de Gripe A que se inició en México alcanzó en junio de 2009 el estadio de pandemia ya que la Organización Mundial de la Salud, Organismo Internacional de Naciones Unidas garante de la seguridad de la salud de la población, de acuerdo con el Plan Mundial de la OMS de Preparación Influenza de 2005 elevó a fase $6^{1}$ esta epidemia que a partir de ese momento es calificada como pandemia.

Durante el transcurso de esta pandemia, desde diversos sectores médicos, expertos, virólogos criticaron, por un lado, la decisión de elevar a fase 6 y determinar la Gripe A como pandemia, por otro, la transparencia en la gestión de esta crisis sanitaria aludiendo conspiraciones ${ }^{2}$ por el alarmismo creado por una enfermedad que no causó más muertes que las que causa la gripe estacional, según datos de la OMS de 2009-2010, así como conflicto de intereses.

El Comité de Emergencias de la OMS encargado de la gestión de la Gripe A, también de las tareas de portavocía e información, formado por 16 personas contaba con 5 miembros que tenían vínculos privados con las principales farmacéuticas ${ }^{3}$ que se encargaron de la producción, desarrollo y venta masiva a todos los países. La Organización Mundial de la Salud nunca reveló la composición del citado comité; fueron los medios de comunicación los que revelaron esta valiosa información en junio de 2010. Disponible en: http://www. bmj.com/content/340/bmj.c2947.full

En nuestra investigación pretendemos mostrar el recorrido de la posible campaña de comunicación desarrollada por parte del lob6y farmacéutico empleando como portavoz de esta crisis sanitaria global a la Organización Mundial de la Salud, consiguiendo que la gripe A fuera una información casi diaria recogida por los principales medios de comunicación durante los 17 meses de crisis.

Con nuestra investigación pretendemos constatar que ante situaciones de crisis, las fuentes más empleadas y citadas por los medios de comunicación son las institucionales u oficiales, preferentemente a cualquier otro tipo de fuente, algo que ya introdujo Camacho

1 Veáse OMS (2005). Plan Mundial de la OMS. Preparación Influenza, Suiza, pp. 36-42.

2 Consulten en COHEN, Deborah, CARTER, Philips (2010). Who and the pandemic flu conspiracies, British Journal of Medicine. Recuperado el 17 de junio de 2010.Disponible en :http://www.bmj.com/content/340/ bmj.c3257

3 Sobre el conflicto de intereses veáse GODLEE, Fiona (2010) "Conflicts of interest and pandemic flu", British Journal of Medicine. Recuperado el 5 de junio de 2010 
Markina (2009), y que pudo ser empleado por el lo66y farmacéutico para sus propios fines de venta y comercialización de fármacos, pues su estrategia de comunicación consistió en configurarse como fuente de información institucional y oficial

A esto se suma el riesgo de ofrecer una visión demasiado alarmista y sensacionalista (Costa Sánchez, 2011) de portadas sobre la gripe A en prensa española, mientras que diversos trabajos en prensa australiana como que muestran que se produjo una cobertura no alarmista pero con un mensaje claro de estar preparado como destacaron Stephenson y Jamieson (2009). Sobre este asunto, coincide un estudio de carácter europeo donde concluye que los medios europeos no dieron una visión alarmista sobre este caso (Duncan, 2009), y otros, donde se asegura que la prensa inglesa fue extremadamente rigurosa (Hilton y Hunt, 2010).

Partimos de la idea de que, en ocasiones, el empleo mayoritario por parte de los medios de comunicación de fuentes institucionales u oficiales puede influir negativamente en la información difundida, ya que estas fuentes pueden responder a intereses particulares manipulando y orientando la opinión pública de la población en beneficio propio, "conocedores de los propios problemas que tienen los medios de comunicación en la difusión de temática científica" (Calvo, 1992 p. 60).

Para ello, hemos hecho un análisis cuantitativo del uso de fuentes en informaciones aparecidas en los periódicos más relevantes de prensa escrita y de mayor difusión nacional en España que son el periódico El País, El Mundo, ABC y Público, entre abril de 2009 y agosto de 2010, meses que se corresponden con el inicio de la crisis sanitaria y con la declaración de finalización de la pandemia.

En este sentido, hemos seleccionando una muestra de los seis primeros meses de esta crisis, debido a que se corresponden con los periodos de mayor interés informativo y donde mayor número de informaciones se difundieron.

También hemos elaborado una clasificación sobre el género periodístico empleado para la difusión de estas informaciones, y un análisis del total de inserciones por parte de los citados medios durante el total del transcurso de los 17 meses de crisis (abril de 2009-agosto 2010) para poder observar el desarrollo informativo que tuvo este caso en los citados medios de prensa escrita nacional.

Para hablar sobre la comunicación realizada por la industria farmacéutica tenemos que hablar del concepto de relaciones públicas que según Cutlip, Center y Broom (2001, p. 30) "son la función directiva que establece relaciones beneficiosas entre una organización y el público o públicos de quienes depende su éxito o fracaso", pero más concretamente de una parte de las mismas que es el lobby y que es pertinente en nuestro objeto de estudio.

Cabe destacar que el lob6y, como apuntan Gruning, Hunt (2000) destaca "por su capacidad para establecer coaliciones, investigar y preparar informes, contactar con gente influyente, preparar testigos y oradores, y centrar el debate pero principalmente, influye en personas legisladoras que pueden adoptar políticas que beneficien a determinados intereses privados o públicos" (p. 743), algo que pudo estar representado por diferentes 
miembros que formaban parte del Comité de Emergencias de la OMS encargados de la gestión de la pandemia de gripe A que, a su vez, pertenecían a grandes empresas farmacéuticas que fueron las que produjeron y vendieron las vacunas en todo el mundo para hacer frente a este tipo de gripe.

En este sentido, recordamos que el lob6y farmacéutico consiguió introducir 5 personas afines a sus intereses comerciales privados entre los 16 miembros del comité de Emergencias de la OMS encargado de gestionar la crisis sanitaria, como descubrieron los principales medios de comunicación en el mundo en junio de 2010 dando a conocer los nombres de las personas que conformaban dicho comité, así como los intereses vinculados que representaban.

Por otra parte, y en el ámbito de las relaciones públicas una de sus principales tareas es la de atraer la atención de los públicos que son objeto del mensaje, con el objetivo de despertar su interés y conseguir de esta forma que se actúe de determinada manera, o se consiga orientar la opinión de la población hacia los intereses de la organización, y en esta tarea "los medios de comunicación son pieza imprescindible en la formación de la opinión pública" (Lippman, 2003, p. 33).

Para ello, el proceso de comunicación realizado desde las relaciones públicas juega un papel decisivo para llamar la atención del mensaje en un mundo globalizado que está saturado de información, y que se articula según Gruning, Hunt (2000), en 4 fases que consisten en "atraer la atención hacia la comunicación, conseguir la aceptación del mensaje, conseguir que dicho mensaje se interprete como se pretendía, y conseguir que dicho mensaje se almacene para usos posteriores" (p. 551).

Esto pudo ocurrir durante la crisis sanitaria de la gripe A, en el que se despertó el interés informativo y mediático hacia todas las informaciones referentes a esta crisis, y del ámbito de la comunicación sanitaria, donde, mayoritariamente y en una primera etapa, se consiguió que se aceptará el mensaje de producción, venta y compra de vacunas por parte de los países para evitar las muertes y el contagio masivo entre la población, a pesar de que existían -y existen- otras muchas enfermedades que provocan más muertes que la citada gripe, y no son objeto de tanto interés informativo de acuerdo con el documental "Pandemia influenza gripe porcina/gripe A o H1N1" de Alterini (2009).

La estrategia de comunicación de la industria farmacéutica combinó el empleo del lob6y dentro del citado comité, así como la utilización de las diversas funciones que permiten las relaciones públicas como son la publicity o información interesada, la publicidad, la agencia de prensa, o los asuntos públicos, en la difusión de información interesada en los medios de comunicación.

Por la importancia que los medios de comunicación tienen en la configuración de la opinión pública, según destacan Rogers, Dearing (1987, p. 555), sobre la "Agenda Setting" de los medios de comunicación, así como McCombs y Shaw (1976, p. 18) que explicaron que "las audiencias no solo aprenden sobre los asuntos públicos y otras cuestiones a través de los medios, sino que aprenden también qué importancia han de otorgar a un tema o asunto por el énfasis que los medios de difusión ponen en él [...]". 
En este punto, cabe destacar que la gripe A, además de convertirse en uno de los principales temas de cobertura para los medios de comunicación, situó a la OMS como el portavoz principal en esta crisis sanitaria, hecho que le dio relevancia y credibilidad a este organismo.

La industria farmacéutica, conocedora de la importancia estratégica de los medios de comunicación, se relaciona con estos a través de las diversas funciones que conforman las RR. PP., como la publicity, así como la función de las RR. PP. de agencia de prensa, cuya principal labor es crear historias de interés informativo para atraer la atención de los medios de comunicación social y captar la atención del público, empleando la publicity como estrategia principal y fundamentando su trabajo de acuerdo con proporcionar noticias de interés para los medios de comunicación, como pudo ocurrir con la noticia sobre el "paciente cero" de la gripe A, un niño llamado Edgar cuya historia ocupó las principales cabeceras de periódicos e informativos internacionales y que fue el punto de inflexión para que la crisis sanitaria de México se convirtiese en una crisis sanitaria mundial.

El objetivo del lobby farmacéutico en la información proporcionada a los medios de comunicación a través de publicity y agencia de prensa era distribuir información de gran interés mediático para que estos procedieran a su cobertura mediática. De esta forma, se difunde el mensaje creado por el lobby orientado hacia las audiencias de interés con el fin de que respondan a los intereses estratégicos de la industria farmacéutica.

A esto se suma que el lobby farmacéutico pudo estar representado en el máximo órgano decisorio sobre la gripe A, que fue el Comité de Emergencias de la OMS, encargado de la portavocía de la crisis, determinación de pandemia, así como del establecimiento de las pautas sanitarias a seguir en cuanto a decisiones vinculantes sobre adquisición y suministro de vacunas por parte de los países miembros.

Es decir, una campaña de comunicación del lob6y farmacéutico que pudo desarrollarse a través de las diversas funciones que engloban las relaciones públicas, así como por la capacidad del citado lob6y para orientar e influir en la toma de decisiones de la OMS.

\section{Metodología}

Sobre el análisis de contenido, Wimmer, Dominick (1996, p. 170) establecen la triple naturaleza del mismo ya que la categorizan como sistemática, objetiva y cuantitativa. De acuerdo con su idea de que "el análisis de contenido debe ser cuantitativo, ya que el propósito de dicha técnica consiste en lograr una representación precisa del conjunto de una serie de mensajes. La cuantificación es un componente vital en dicha búsqueda de la precisión".

Asimismo, "el análisis de contenido es una técnica de investigación destinada a formular, a partir de ciertos datos, inferencias reproducibles y válidas que puedan aplicarse a su contexto" (Krippendorf, 1990, p. 28). Hemos decidido desarrollar un análisis de carácter cuantitativo que nos permitirá obtener datos que podremos comparar y contrastar en nuestra búsqueda para ser lo más precisos en nuestro objeto de estudio. 
Para llevar a cabo nuestra investigación hemos efectuado un vaciado de prensa de la edición impresa de ABC, El Mundo, El País y Público, entre el 26 de abril de 2009 y el 10 de agosto de 2010 (fecha de inicio, de desarrollo, y de fin de la crisis sanitaria de la gripe A), donde hemos recogido todos los documentos en los que aparecían los términos: "gripe A, gripe porcina, virus H1N1, o informaciones que hicieran referencia a la Gripe A" en los citados medios de comunicación.

Posteriormente, hemos seleccionado una muestra de los 6 primeros meses del total de 17 meses en los que se desarrolló la citada crisis sanitaria, correspondientes a los períodos: no pandémico, pre-pandémico y pandémico, es decir, en los momentos de más interés mediático antes de alcanzar el período de menor interés informativo en la era pospandémica.

De entre los 6 meses seleccionados nos hemos encontrado con un total de 1.036 unidades de análisis que se corresponden a las informaciones aparecidas en El País, ABC, El Mundo y Público y a las que hemos realizado dos tipos de análisis de contenido.

En primera instancia, todas las informaciones las hemos sometido a una distinción sobre a qué género periodístico pertenecen: género informativo, género interpretativo y opinión, de acuerdo con la definición que para cada uno de estos términos hace Grijelmo (1997).

Dentro del género informativo distinguimos: noticias, fotonoticias, y reportajes gráficos.

\begin{tabular}{|l|l|l|l|}
\hline & Noticias & Fotonoticias & Reportajes gráficos \\
\hline Género informativo & & & \\
\hline
\end{tabular}

En el género interpretativo incluimos reportajes, entrevistas, crónicas y análisis.

\begin{tabular}{|l|l|l|l|l|}
\hline & Reportajes & Entrevistas & Crónicas & Análisis \\
\hline Género interpretativo & & & & \\
\hline
\end{tabular}

Asimismo, forman parte del género opinión: editoriales, artículos de opinión, columna o comentario, viñeta gráfica, y carta al director.

\begin{tabular}{|l|l|c|c|c|c|}
\hline & Editoriales & $\begin{array}{c}\text { Artículo de } \\
\text { opinión }\end{array}$ & $\begin{array}{c}\text { Columna o } \\
\text { Comentario }\end{array}$ & Viñeta gráfica & Carta al director \\
\hline Género Opinión & & & & & \\
\hline
\end{tabular}

Para cada unidad de análisis hemos asignado una nomenclatura alfa-numérica que se corresponde con el tipo de medio, el número de orden de la unidad de análisis por orden numérico, el género periodístico al que corresponde, el tipo de información, la fecha a la que corresponde en formato (día, mes, y año) con dos dígitos, y una letra en orden alfabético en el caso de que apareciera más de una información en un mismo día, a modo de diferenciarlas por el orden de publicación en el medio, es decir, (A,B,C,...). 
Nomenclatura del medio de comunicación al que corresponde

\begin{tabular}{|c|c|}
\hline Medio de comunicación & Nomenclatura \\
\hline El País & $\mathrm{P}$ \\
\hline El Mundo & $\mathrm{M}$ \\
\hline ABC & $\mathrm{A}$ \\
\hline Público & $\mathrm{PU}$ \\
\hline
\end{tabular}

Nomenclatura para el tipo de género e información

\begin{tabular}{|c|c|}
\hline Género informativo & $\mathrm{I}$ \\
\hline Noticias & $\mathrm{N}$ \\
\hline Fotonoticias & $\mathrm{F}$ \\
\hline Reportajes informativos & $\mathrm{R}$ \\
\hline
\end{tabular}

\begin{tabular}{|c|c|}
\hline Género interpretativo & IN \\
\hline Reportajes & $\mathrm{R}$ \\
\hline Entrevistas & $\mathrm{E}$ \\
\hline Crónicas & $\mathrm{C}$ \\
\hline Análisis & $\mathrm{A}$ \\
\hline
\end{tabular}

\begin{tabular}{|c|c|}
\hline Género opinión & $\mathrm{O}$ \\
\hline Editorial & $\mathrm{E}$ \\
\hline Artículo de opinión & $\mathrm{A}$ \\
\hline Columna o comentario & $\mathrm{C}$ \\
\hline Viñeta gráfica & $\mathrm{V}$ \\
\hline Carta al director & $\mathrm{D}$ \\
\hline
\end{tabular}

\section{Nomenclatura en referencia a la fecha de la unidad de análisis}

\begin{tabular}{|c|c|c|}
\hline Día $/ 00 /$ & Mes $/ 00 /$ & Año $/ 0000 /$ \\
\hline
\end{tabular}

\section{Nomenclatura en cuanto al orden de aparición de la información}

En el caso, de que haya publicada más de una unidad de análisis en el mismo día asignamos a las mismas una letra final tras la fecha en orden alfabético (A, B, C, D...), para saber el orden de aparición de la misma.

\begin{tabular}{|c|c|}
\hline Primera información & A \\
\hline Segunda información & B \\
\hline Tercera información & C \\
\hline Cuarta información & D \\
\hline$\ldots$ & $\ldots$ (Siguiendo orden alfabético) \\
\hline
\end{tabular}


Tras este primer análisis de contenido, a las unidades las hemos sometido a un segundo análisis para conocer qué tipo de fuentes periodísticas han empleado para la elaboración de la citada información y para ello hemos diferenciado entre:

\begin{tabular}{|c|c|}
\hline Tipo de fuente & Nomenclatura \\
\hline Fuentes institucionales & FI \\
\hline Fuentes expertas & FE \\
\hline Fuentes implicadas & FIM \\
\hline Fuentes agencias & FA \\
\hline Fuentes medios & FM \\
\hline Fuentes otros & FO \\
\hline
\end{tabular}

Fuentes institucionales (FI): hacen referencia a los organismos oficiales en materia sanitaria y de carecer gubernamental que proporcionan lo que se conoce como información oficial.

Fuentes expertas (FE): en este conjunto podemos aglutinar a médicos, virólogos, profesionales en materia de crisis sanitarias, de crisis comunicacionales, todos aquellos especialistas que no se pertenecen o se circunscriben al flujo informativo oficial.

Fuentes implicadas (FIM): en este apartado hablamos de testigos presenciales, personas que viven en primera personas los acontecimientos de la noticia que está sucediendo; serían los protagonistas de la noticia, los que están en primera persona en el acontecimiento.

Fuentes agencias (FA): hace referencia a las agencias de noticias como EFE, Europa Press, Reuters, American Press, entre otras, que suelen utilizarse por los medios de comunicación como fuentes para la elaboración de la noticia que, posteriormente, publicarán en sus respectivos medios de comunicación.

Fuentes medios (FM): aunque suele ser poco habitual, en ocasiones, se utilizan como fuentes periodísticas lo publicado en otros medios de comunicación a los cuales se cita, por lo que resulta relevante que a la hora de realizar nuestra investigación tengamos en cuentan el empleo, como fuente, de otro medio de comunicación.

Fuentes otros (FO): nos serviría como una categoría abierta ante el empleo de otro tipo de fuentes que no sean las convencionales.

Para cada unidad de análisis, hemos elaborado un cuadro que cuenta con la nomenclatura aportada por el primer análisis de contenido, y el número de fuentes empleadas. A continuación, mostramos una de estas fichas:

Tabla 1

\begin{tabular}{|c|c|c|c|c|c|c|c|}
\hline & FI & FE & FIM & FA & FM & FO & TOTAL \\
\hline P1: Pin r 2604 09_02 A & 3 & & & & & & 3 \\
\hline
\end{tabular}


En este ejemplo observamos que se trata de una unidad de análisis de El País (P), concretamente, de la número (1), que pertenece al género interpretativo (in), que se corresponde a la fecha 26 04 09, y que es la primera información de ese día que viene definida por la letra $(\mathrm{A})$.

Esta unidad de análisis consta de un total de 3 fuentes, concretamente del tipo institucionales.

De esta forma, hemos aplicado estos dos tipos de análisis, tanto de contenido para conocer el tipo de género periodístico de las unidades de análisis, como un análisis cuantitativo con respecto al uso de fuentes empleadas en la muestra de 1.036 documentos, anteriormente mencionados.

Por último, hemos elaborado un recuento total de todas las portadas, e inserciones de información durante el período abril de 2009-agosto de 2010 sobre los términos vinculados a gripe A, virus AHN1, gripe porcina, o gripe, en los periódicos objeto de estudio consiguiendo determinar la frecuencia de publicación sobre esta temática.

\section{Resultados obtenidos}

Tras el análisis realizado, las fuentes más utilizadas en ABC, El Mundo, El País, y Público son: las fuentes institucionales con un 66\% (1.806); las fuentes implicadas, con un 18\% (500); las fuentes expertas, con un 11\% (292); las fuentes medios de comunicación, con un $4 \%$ (91); las fuentes agencias, con un 2\% (49), y un 0\% para fuentes Otros.

Tabla 1. Total fuentes

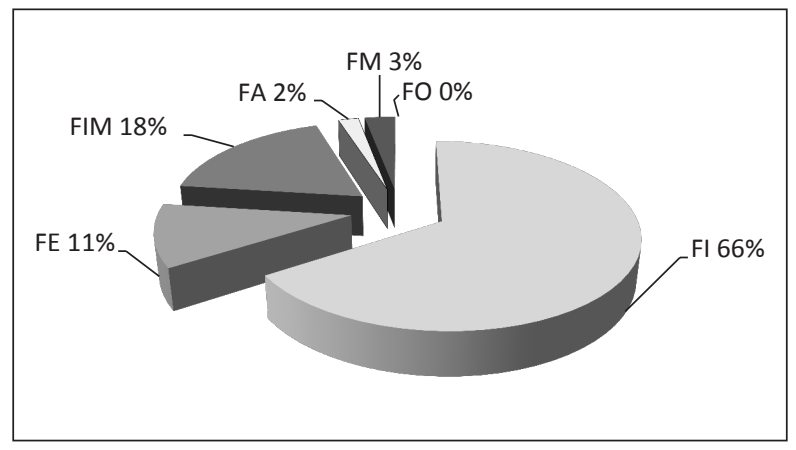

Fuente: elaboración propia

Ante crisis informativas, observamos que las fuentes más empleadas son las fuentes institucionales probablemente porque los medios prefieran estas por su fiabilidad, notoriedad, y reputación, por encima de cualquier otro tipo de fuente de información.

\section{Total fuentes empleadas}

\section{$\mathrm{ABC}$}

ABC emplea en un 69\% (503 unidades) las fuentes institucionales. Le siguen las fuentes implicadas con un 17\% (126 unidades); las fuentes expertas han sido empleadas en un $8 \%$ 
(59). Por orden de importancia, continúan las fuentes: medios de comunicación con un $4 \%$ (26); fuentes agencias, con un $1 \%(10)$, y con un $0 \%$ la categoría de fuentes Otros (0).

Tabla 2. ABC

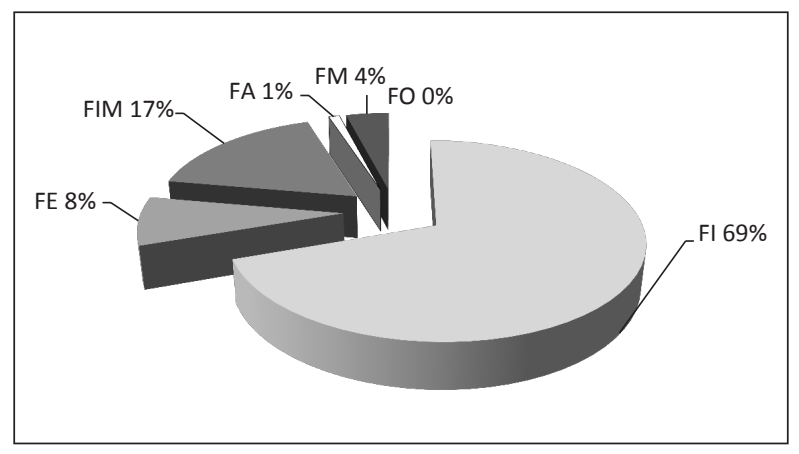

Fuente: elaboración propia

En ABC, el empleo de las fuentes institucionales es del 69\%, lo que prepondera este tipo de fuentes con respecto al resto; tan solo un $31 \%$ corresponde a otro tipo de fuentes con las que poder contrastar y completar las informaciones que aporten otros puntos de vista.

\section{EL MUNDO}

Las fuentes más utilizadas por El Mundo son las fuentes institucionales con un 66\% (486 unidades); les siguen: las implicadas con un 19\% (151); las fuentes expertas con un $11 \%$ (83); y con un $4 \%$, respectivamente, (29 unidades entre ambas), encontramos las fuentes medios de comunicación y las fuentes agencias.

Tabla 3. El Mundo

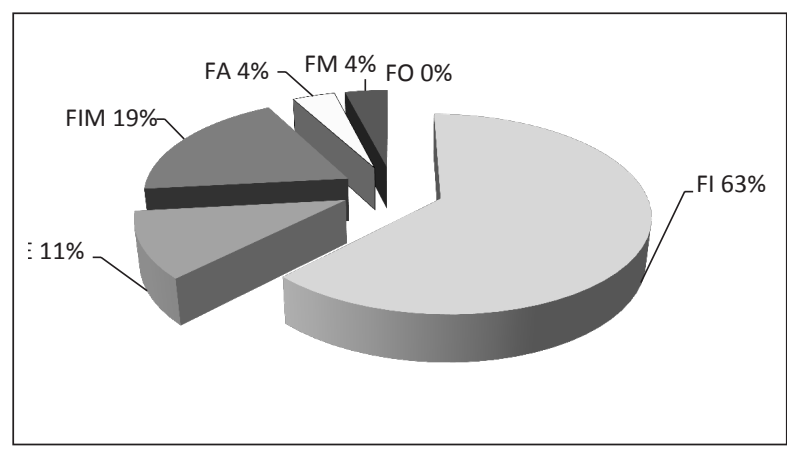

Fuente: elaboración propia

El Mundo también emplea por encima del 50\% las fuentes institucionales, se sitúa en un $63 \%$ en la utilización de estas por encima de cualquier otro tipo de fuente informativa lo que implica su preferencia y orientación de informaciones hacia estas fuentes sobre otras que pueden aportar mayor diversidad a la información global. 


\section{EL PAÍS}

El País utiliza las fuentes institucionales en un 64\% (489 unidades); le siguen las fuentes implicadas con un 19\% (148). Tras estas, las fuentes expertas, con un 14\% (104); las fuentes medios de comunicación, con un $2 \%$ (16); las fuentes agencias con un $1 \%$, y 0 , para fuentes otros.

Tabla 4. El País

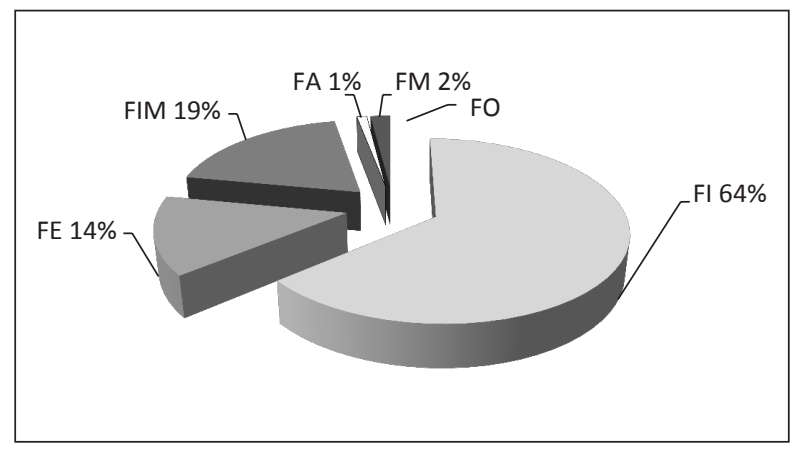

Fuente: elaboración propia

Nuevamente, nos encontramos con la utilización de fuentes institucionales con respecto a cualquier otro tipo de fuentes por encima del $50 \%$, concretamente, un $64 \%$ en este caso, lo que implica mayor predominio de estas, y merma la capacidad de la ciudadanía para contar con un mayor número de fuentes que aporten diferentes puntos de vista.

\section{PÚBLICO}

Público emplea las fuentes institucionales en un 69\% (325 unidades); tras estas encontramos las fuentes implicadas con un 16\% (75); le siguen: las fuentes expertas, con un $10 \%$ (46); las fuentes medios de comunicación, con un 4\% (20); con un 1\% (7) tenemos a las fuentes agencias, y con un $0 \%$ a fuentes Otros.

Tabla 5. Público

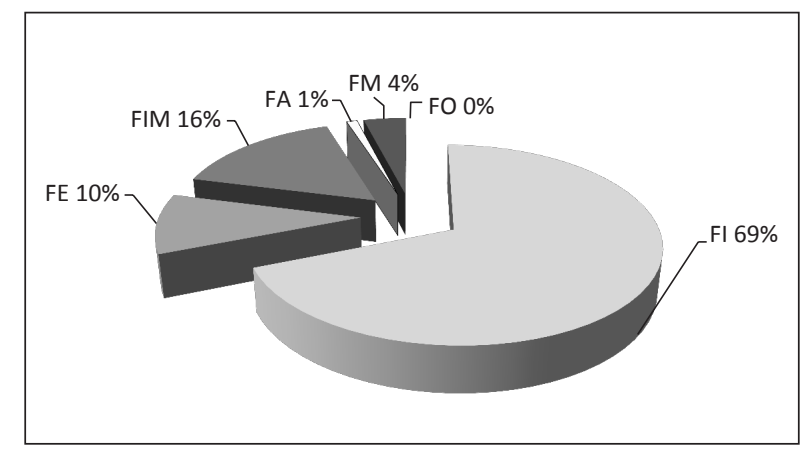

Fuente: elaboración propia

Al igual que el resto de medios de comunicación anteriores, Público emplea en casi un $70 \%$ las fuentes institucionales (69\%), con respecto a otro tipo de fuentes. 


\section{Total géneros periodísticos}

\section{$\mathrm{ABC}$}

El género periodístico más utilizado por el periódico ABC fue el informativo con un 50\% (158 unidades); el género interpretativo, con un 46\% (147), y el género opinión, con un 14\% (14).

Tabla 6. Total géneros ABC

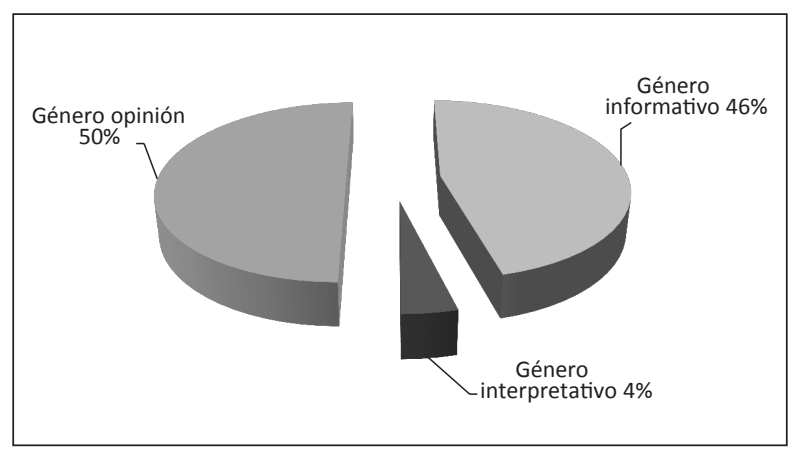

Fuente: elaboración propia

El género informativo 50\% supera a la utilización del género interpretativo aunque por poco tan solo un $4 \%$, es decir, $46 \%$, por lo que se dan informaciones casi de forma igualitaria aunque con cierta preferencia por las informaciones de carácter informativo e interpretativas.

El género informativo en $\mathrm{ABC}$ se empleó durante el mes de agosto con un 15\% (46 unidades); le sigue julio, con un $13 \%$ (42); septiembre, con un $8 \%$ (26); mayo, con un $6 \%$ (20); junio, con un $6 \%$ (18), y abril, con un $2 \%(6)$.

Tabla 7. Género informativo $A B C$

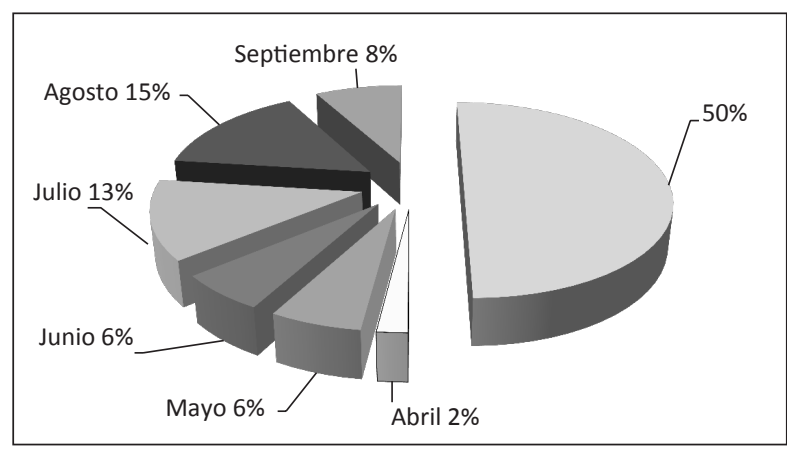

Fuente: elaboración propia

Durante el mes de julio constatamos mayor número de informaciones debido a que nos encontrábamos inmersos en plena pandemia que había sido declarada el anterior 
11 de junio de 2009, lo que despertó gran interés informativo por parte de los medios de comunicación.

El género interpretativo se empleó con un 44\% (64 unidades) en el mes de mayo; le siguen: abril, con un 19\% (28); julio, con un 17\% (25); agosto, con un 12\% (17); junio, con un $5 \%(8)$, y septiembre, con un $3 \%$ (5).

Tabla 8. Género interpretativo ABC

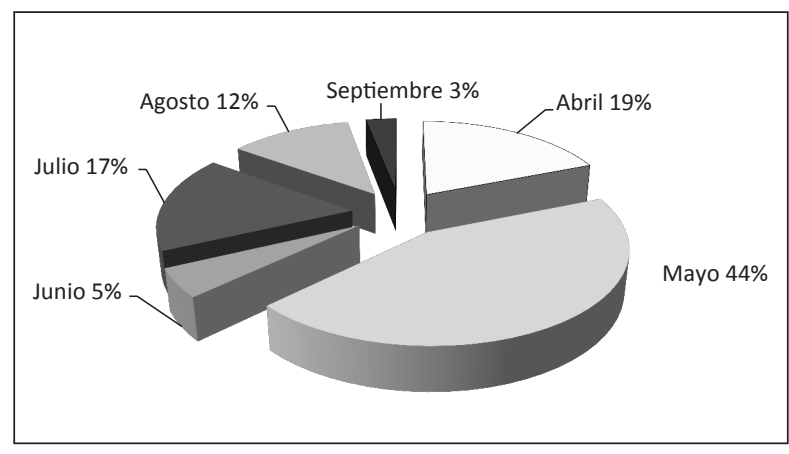

Fuente: elaboración propia

Asimismo, vemos que durante el mes de mayo hubo mayor número de informaciones de género interpretativo debido, probablemente, a la incertidumbre, rapidez de las informaciones y desconocimiento de lo que iba a ocurrir, por lo que se preferían más informaciones interpretativas que meramente informativas.

El género opinión se empleó en un 43\% (6 unidades) en el mes de mayo; en un 21\% (3), en julio; con un 14\% (y 2 unidades), respectivamente, los meses de abril y agosto; con un 7\% (1) tenemos el mes de septiembre, y con 0\% el mes de junio.

Tabla 9. Género opinión ABC

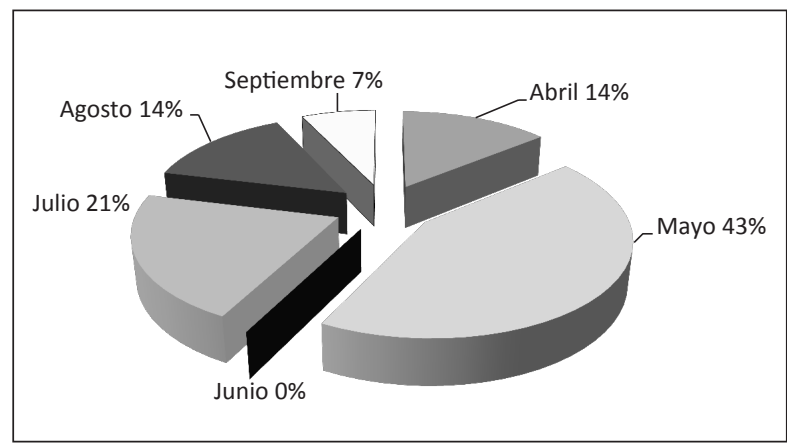

Fuente: elaboración propia

Asimismo, constatamos cómo antes de la declaración de la pandemia en el mes de junio, el periódico ABC publicó un mayor número de artículos de opinión debido a la importancia de ofrecer su personal opinión acerca de los acontecimientos. 


\section{EL MUNDO}

El género periodístico más utilizado por El Mundo fue el informativo con un 50\% (158 unidades); el género interpretativo con un 46\% (147), y el género opinión con un 14\% (14).

Tabla 10. Total géneros El Mundo

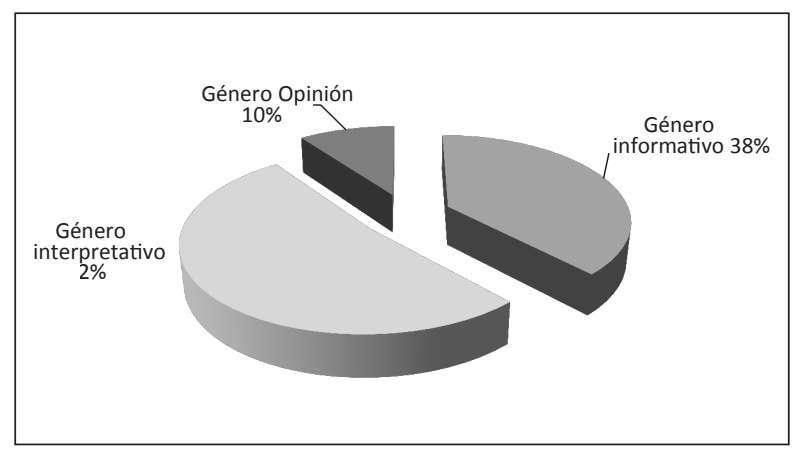

Fuente: elaboración propia

Al igual que en otros medios, El Mundo por encima del 50\%, concretamente, el 52\% empleó el género interpretativo con respecto a otro tipo de género lo que constata la preferencia de este medio por ofrecer información con cierta interpretación en lugar de otro tipo de géneros quizá por el carácter sensible de este tipo de informaciones de crisis sanitaria donde se prepondere la información a la opinión.

El género informativo se empleó en el periódico el Mundo en un 35\% (38 unidades) en el mes de julio; en un 32\%, en el mes de agosto con (32 unidades); le sigue el mes de septiembre, con un 25\% (27); con un 5\% respectivamente, (y 5 unidades) en los meses de mayo y junio, y por último, en abril, con un $1 \%$ (1).

Tabla 11. Género informativo El Mundo

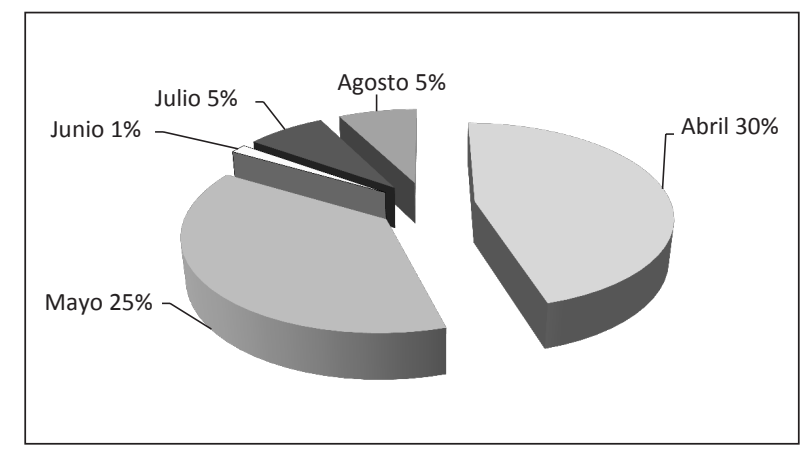

Fuente: elaboración propia

Durante el mes de julio nos encontramos con un mayor número de informaciones con un $35 \%$, y en agosto con un $30 \%$, período que corresponde al pleno desarrollo de la pandemia de gripe $\mathrm{A}$. 
El género interpretativo se empleó en el periódico El Mundo con mayor intensidad en el mes de mayo en un 51\% (74 unidades); le sigue el mes de abril en un 23\% (33). Los siguientes, en orden de importancia, son: el mes de julio, con un 12\% (17); junio, con un $6 \%$ (9); septiembre, con un 5\% (8), y con un 3\% (5) en el mes de agosto.

Tabla 12. Género interpretativo El Mundo

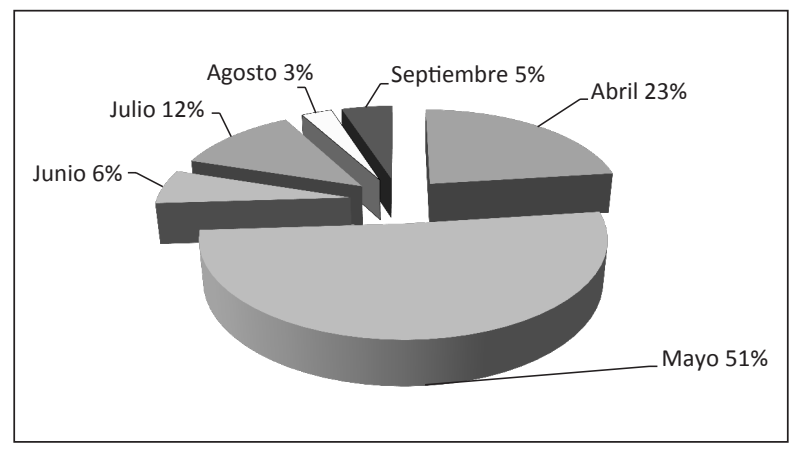

Fuente: elaboración propia

Podemos observar cómo durante el mes de mayo, previo a la declaración de pandemia, se publicó un mayor número de informaciones de carácter interpretativo, en gran medida, por la posibilidad que ofrece este género para aportar una visión más clara en un momento delicado de crisis sanitaria previa a la declaración de pandemia.

El género opinión se empleó en el periódico El Mundo con mayor intensidad en el mes de mayo en un 28\% (8 unidades); le sigue el mes de agosto, con 24\% (7); luego, los meses de julio y septiembre con un 17\% (5) cada uno, y un 14\% (4) el mes de abril.

Tabla 13. Género opinión El Mundo

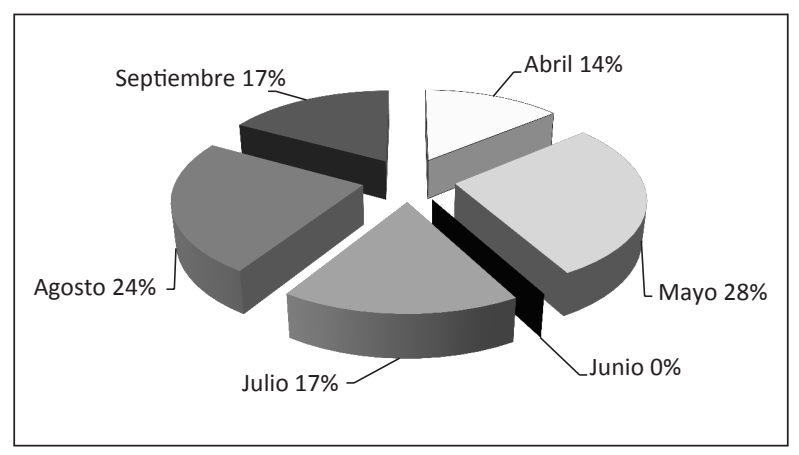

Fuente: elaboración propia

Durante el mes de mayo, previo a la declaración de pandemia, así como en agosto, mes de pleno desarrollo de la misma, nos encontramos con un mayor número de informaciones de carácter de opinión, en gran medida, por el interés de ofrecer la opinión del medio en el período pre-pandémico y pandémico. 


\section{EL PAÍS}

El género periodístico más utilizado por el periódico El País fue el interpretativo con un 63\% (154 unidades); le sigue el género informativo, con un 31\% (76), y el género opinión, con un $6 \%(15)$.

Tabla 14. Total géneros El País

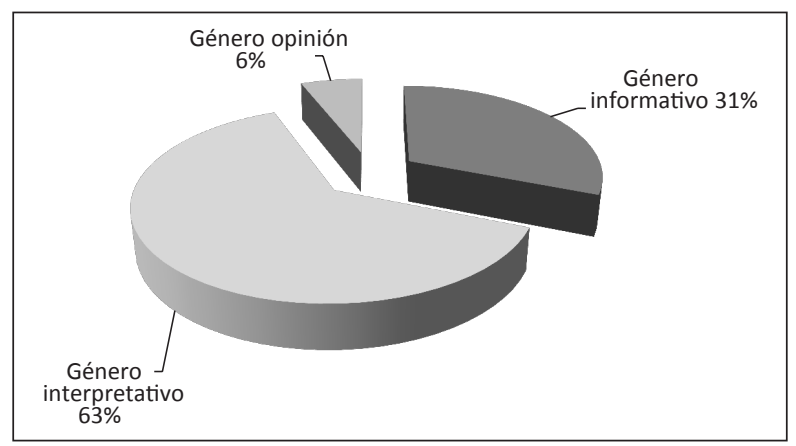

Fuente: elaboración propia

A diferencia de ABC, el periódico El País al igual que El Mundo empleó el género interpretativo por encima del informativo lo que indica su preferencia por ofrecer informaciones con la valoración del periodista, más allá de resultar meramente informativas.

El género informativo se empleó en el periódico El País en un 37\% (28 unidades) durante el mes de septiembre; le siguen: el mes de agosto, en un 29\% (22); en junio se alcanzó un 17\% (13); en abril se llegó al 7\% (5), y por último, mayo, con un 2\% (2).

Tabla 15. Género informativo El País

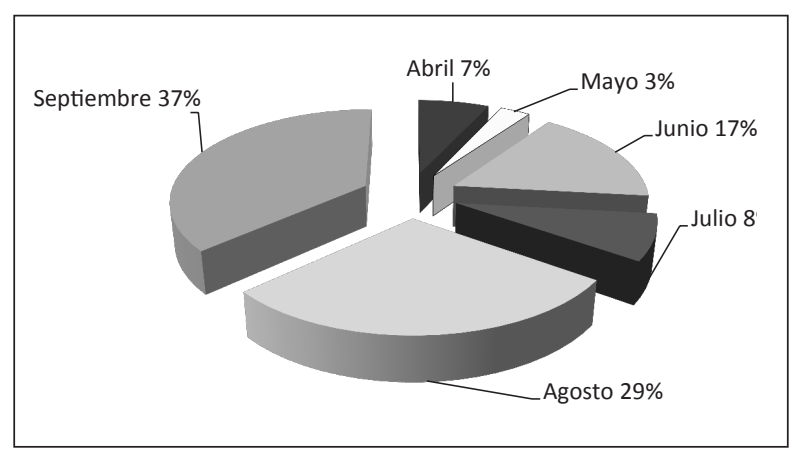

Fuente: elaboración propia

Durante el mes de septiembre cabe destacar que se sucedieron muchas actuaciones en las que se apelaba a la vacunación de la población lo que se corresponde con un mayor número de informaciones al respecto, lo que podría explicar este aumento en este género durante el citado mes. Asimismo, el mes de Agosto corresponde al pleno desarrollo de la pandemia, lo que puede entenderse como mayor número de informaciones en los medios, debido al interés mediático de las mismas. 
El género interpretativo fue empleado por El País con mayor incidencia en el mes de mayo con un 44\% (68 unidades); le siguen: julio, con un 23\% (36); abril, con un 16\% (25); junio, con un $8 \%$ (12); agosto con un 6\% (10), y septiembre, con un $2 \%$ (3).

Tabla 16. Género interpretativo El País

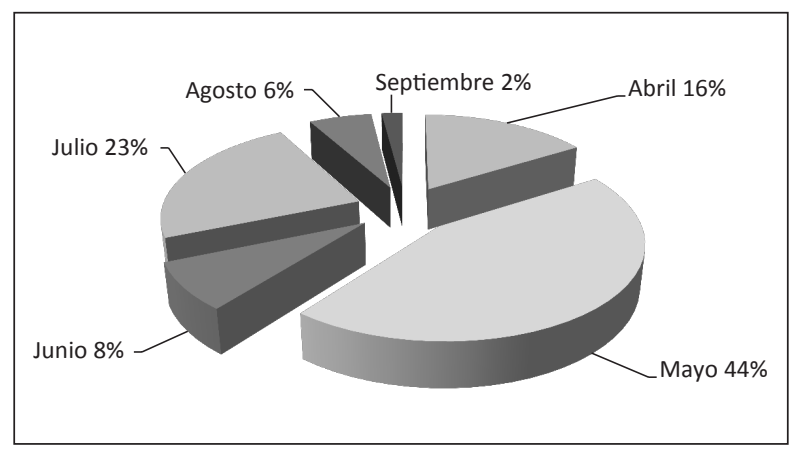

Fuente: elaboración propia

A igual que sucedía en otros medios de comunicación, durante el mes de mayo, momento pre-pandémico, se sucede un mayor número de informaciones que se corresponden con el género interpretativo, es decir, mayor valoración en un momento de incertidumbre ante la inminente declaración de pandemia por parte de la OMS durante el siguiente mes de junio.

El País empleó el género opinión: con mayor incidencia en un 40\% (6 unidades) en el mes de mayo; le siguen junio y septiembre, con un 20\% (3), respectivamente; abril, con un $13 \%(2)$; julio, con un $7 \%$ (1), y agosto con un $0 \%$.

Tabla 17. Género opinión El País

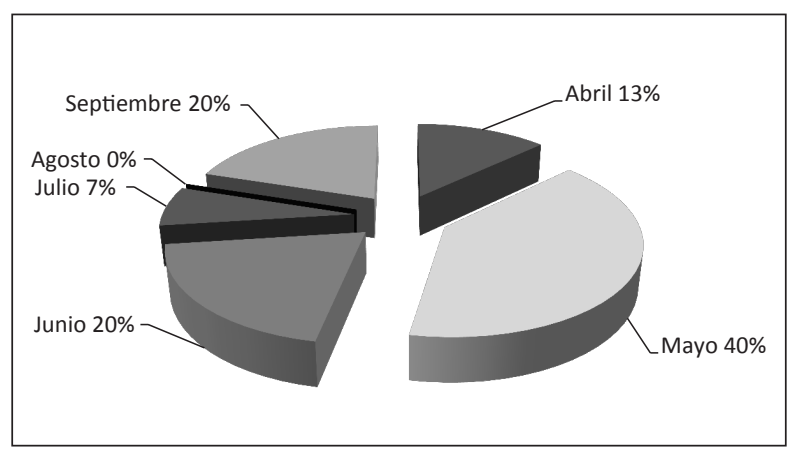

Fuente: elaboración propia

Al igual que en otros medios analizados, el género de opinión se empleó con mayor incidencia en el mes de mayo, momento pre-pandémico de gran interés mediático, debido a la incertidumbre del momento previo a la declaración de pandemia mundial. 


\section{Público}

El género informativo, con un 54\% (103 unidades), fue el más empleado; le siguen el género interpretativo, con un 37\% (71), y el género opinión, con un 9\% (9).

Tabla 18. Total géneros público

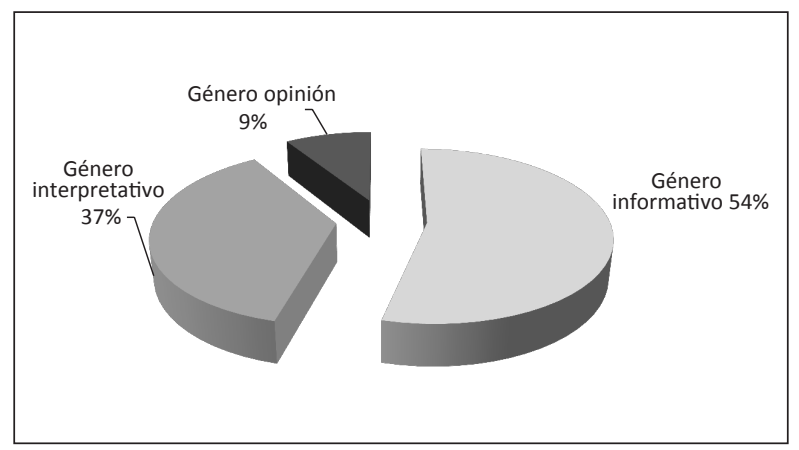

Fuente: elaboración propia

Observamos que en Público se da un mayor número de informaciones publicadas referidas al género informativo por encima del 50\%, concretamente, del 54\%, como se da en el periódico ABC, y en contraste con el periódico El Mundo y El País, donde prepondera el género interpretativo sobre el informativo.

El género informativo se empleó con mayor incidencia durante los meses de julio y agosto con un 26\% y (27 unidades); mayo con un 23\% (24); septiembre, con un 13\% (13); junio, un $10 \%$ (10), y abril, con un $2 \%(2)$.

Tabla 19. Género informativo público

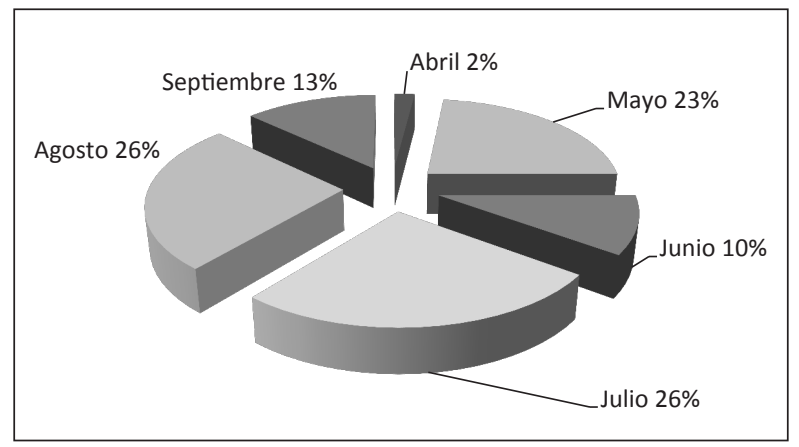

Fuente: elaboración propia

Los meses de mayor incidencia informativa se dan en pleno desarrollo de la pandemia, esto es, los meses de verano de julio y agosto, así como en el momento pre-pandémico, antes de que la OMS declarara, en junio, la pandemia. 
El género interpretativo se empleó con mayor incidencia: durante el mes de mayo con un 30\% (21 unidades); abril, con un 24\% (17); junio y julio que alcanzaron un 13\% (9), respectivamente; con un $11 \%(8)$, agosto, y con un 10\% (3), septiembre.

Tabla 20. Género interpretativo

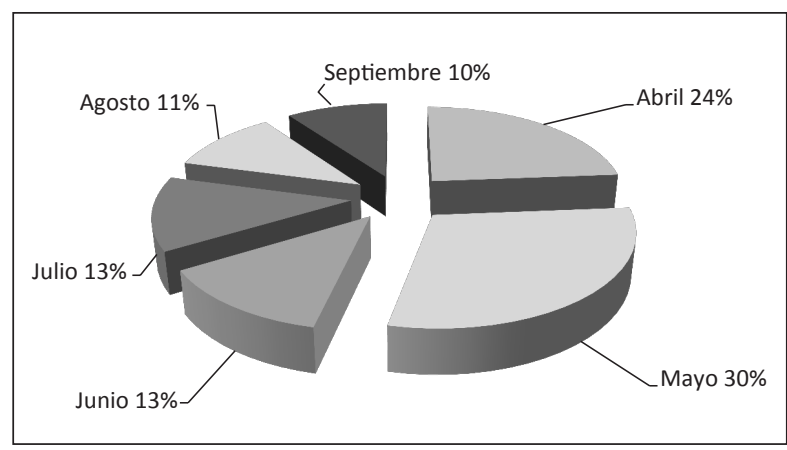

Fuente: elaboración propia

Al igual que sucede en los otros medios analizados, durante el mes de mayo, previo a la declaración de la pandemia en el mes junio, se dio un mayor número de informaciones relacionadas con el género interpretativo donde se observa la importancia de aportar comunicaciones más allá de lo meramente informativo.

El género opinión se empleó con una mayor incidencia durante los meses de mayo y agosto con un 29\% (5 unidades), respectivamente. En orden de importancia le siguen: septiembre, con un 18\% (3); con un 12\% (2) encontramos a abril y julio, y con un $0 \%$, el mes de junio.

Tabla 21. Género opinión público

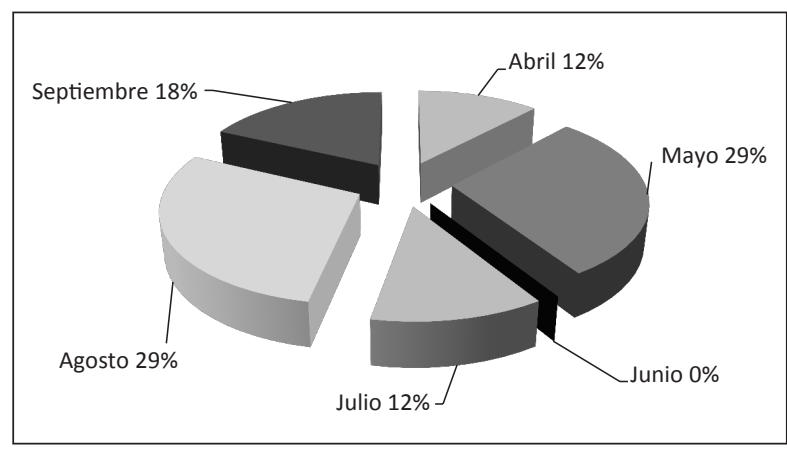

Fuente: elaboración propia

Cabe destacar que el género de opinión se dio en mayor incidencia en Público durante el mes de mayo pre-pandémico, y en agosto, mes de desarrollo de la pandemia. Al igual que en el resto de periódicos analizados, nos encontramos que se ofrecía la opinión del medio con mayor incidencia en estos periodos. 


\section{Total inserciones}

\section{Total portadas 2009}

Tabla 22

\begin{tabular}{|c|c|c|c|c|c|c|c|c|c|}
\hline Periódicos & Abril & May & Jun & Jul & Agosto & Sept & Oct & Nov & Dic \\
\hline El País & 5 & 15 & 5 & 12 & 6 & 6 & 0 & 2 & 0 \\
\hline El Mundo & 5 & 13 & 2 & 14 & 8 & 4 & 0 & 2 & 0 \\
\hline Abc & 4 & 12 & 4 & 11 & 13 & 1 & 1 & 2 & 0 \\
\hline Público & 5 & 7 & 4 & 5 & 7 & 2 & 0 & 1 & 0 \\
\hline
\end{tabular}

Fuente: elaboración propia

Tabla 23.

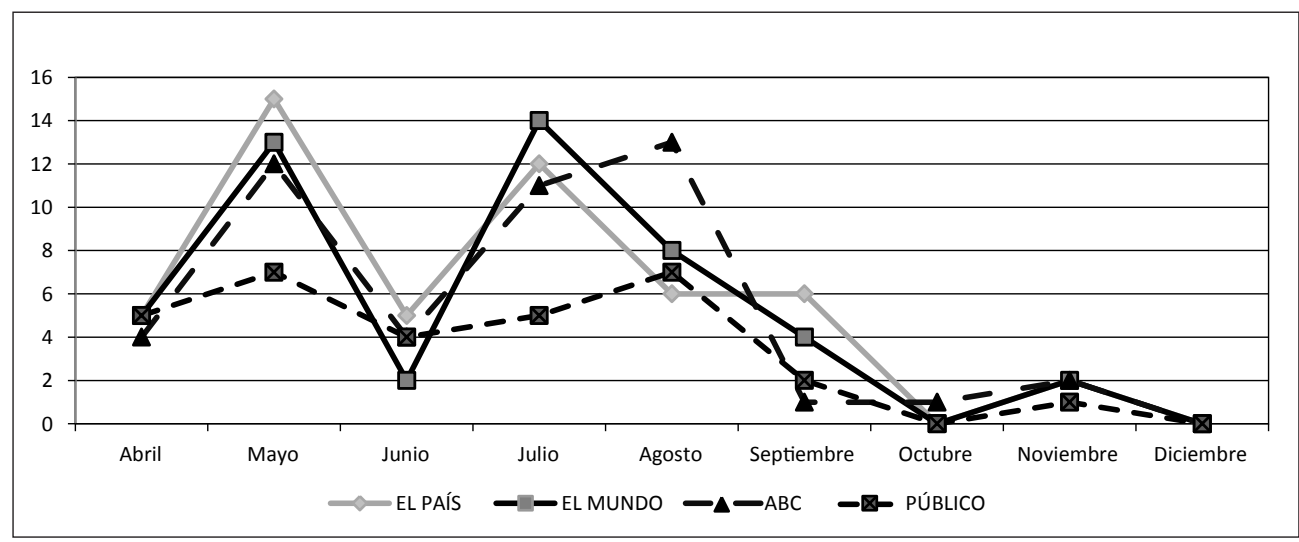

Fuente: elaboración propia

En cuanto al número total de portadas, el periódico El País publicó durante 2009 un total de 51 portadas sobre gripe A, El Mundo y ABC publicaron 48, y Público, 31. Los meses donde se publicó un mayor número de portadas sobre gripe A en 2009 corresponden en la mayoría de los periódicos: a mayo, con 47, y a julio, con 42. En referencia al resto de meses, en abril se publicaron 19 portadas; en junio, 15; en agosto, 34; en septiembre, 13; en octubre, 1 ; en noviembre, 7 , y en diciembre, 0 .

Los meses en los que se publicó un mayor número de portadas, concretamente, mayo y julio, se corresponden con el período pre-pandémico (mayo), y pandémico (junio), momentos de mayor interés informativo por parte de los medios de comunicación. 


\section{Tabla 24}

Total inserciones 2009

\begin{tabular}{|c|c|c|c|c|c|c|c|c|c|}
\hline Periódicos & Abril & May & Jun & Jul & Ago & Sep & Oct & Nov & Dic \\
\hline El País & 32 & 89 & 28 & 48 & 32 & 34 & 18 & 24 & 20 \\
\hline El Mundo & 38 & 89 & 13 & 61 & 44 & 42 & 17 & 15 & 8 \\
\hline Abc & 33 & 92 & 26 & 71 & 66 & 32 & 22 & 25 & 0 \\
\hline Público & 21 & 50 & 18 & 36 & 40 & 23 & 11 & 12 & 3 \\
\hline
\end{tabular}

Fuente: elaboración propia

Tabla 25.

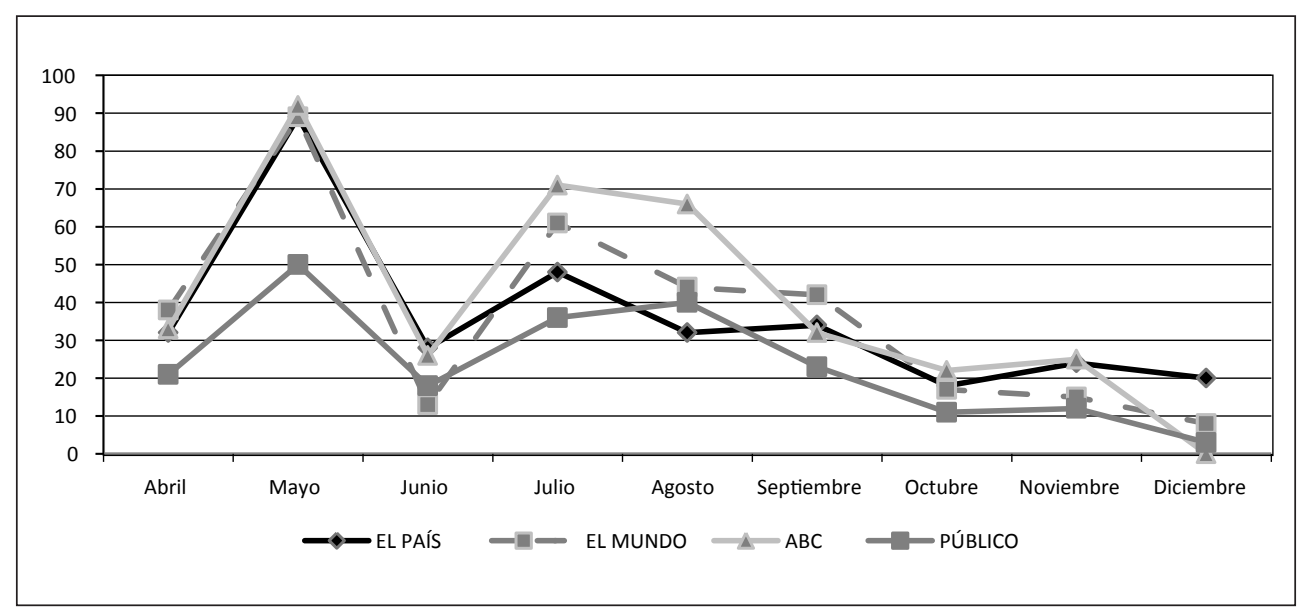

Fuente: elaboración propia

En mayo se publicó un mayor número de informaciones sobre gripe A, concretamente 320; julio contó con 216; agosto, con 182; abril con 124; septiembre, con 131; junio, con 85; noviembre, con 76; octubre, con 68, y diciembre, con 31.

Por medios de comunicación, ABC fue el periódico que más informaciones publicó sobre gripe A (367), seguido de El Mundo con 327; El País, con 325, y Público, con 214.

Asimismo, constatamos que durante el periodo pre-pandémico, es decir, mayo y durante los meses después de la declaración de pandemia en el mes de junio, esto es el trimestre julio-agosto-septiembre contamos con un mayor número de inserciones debido a que nos encontrábamos en un momento de mayor interés mediático de esta crisis sanitaria mundial que se desarrolló durante los 17 meses de esta crisis global. 
Total portadas 2010

Tabla 26

\begin{tabular}{|c|c|c|c|c|c|c|c|c|}
\hline Periódicos & En & Feb & Mar & Abril & May & Jun & Jul & Agos \\
\hline El Páis & 0 & 0 & 0 & 0 & 0 & 0 & 0 & 2 \\
\hline El Mundo & 0 & 1 & 0 & 0 & 0 & 0 & 0 & 1 \\
\hline Abc & 0 & 0 & 0 & 0 & 0 & 0 & 0 & 0 \\
\hline Público & 0 & 0 & 0 & 0 & 0 & 0 & 0 & 0 \\
\hline
\end{tabular}

Elaboración propia.

Tabla 27.

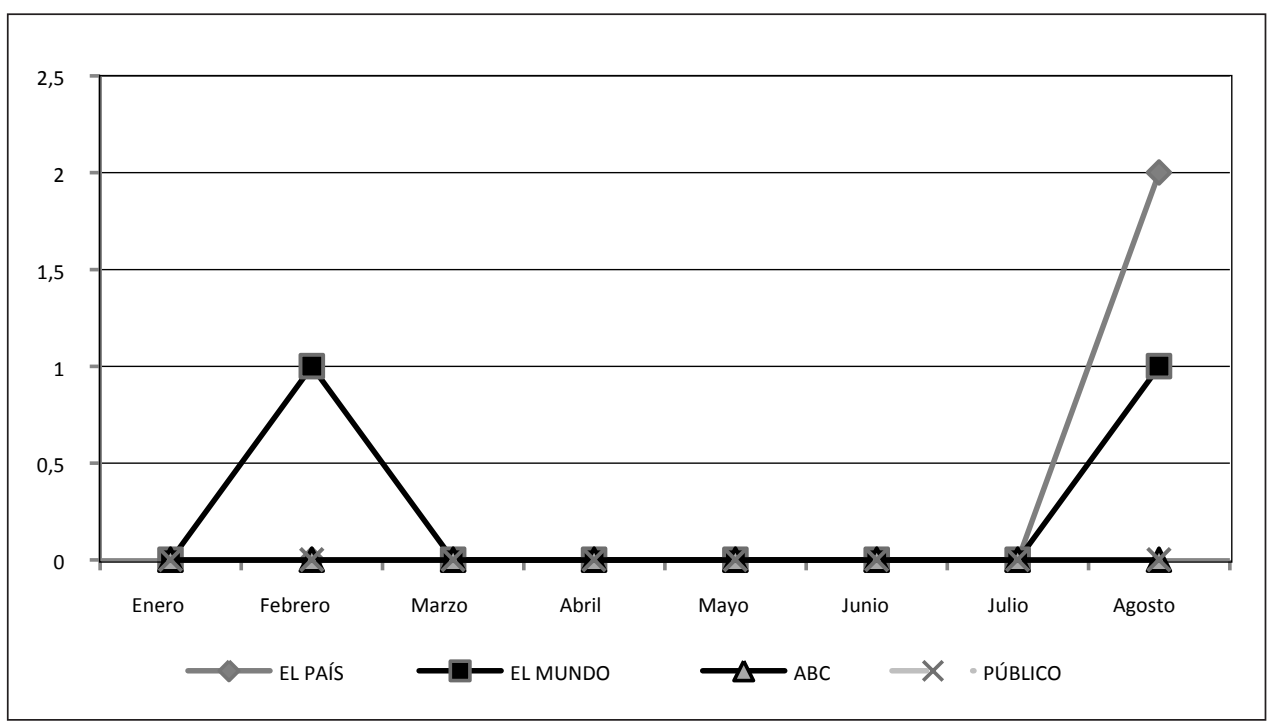

Fuente: elaboración propia

En cuanto al número total de portadas, el periódico El País publicó durante 2010 un total de 2 portadas sobre gripe A, y El Mundo, 1; ABC y Público no registraron portadas con esta temática.

En agosto de 2010 se publicó un mayor número de portadas sobre gripe A; este mes se corresponde con el momento en el que la OMS dio por finalizada la pandemia.

En este gráfico, observamos cómo solo la finalización de la pandemia declarada por la Organización Mundial de la Salud durante el mes de agosto despertó el interés informativo a los medios de comunicación que durante los meses previos habían constatado con sus publicaciones la falta de interés hacia esta temática, con un menor número de informaciones publicadas al respecto. 


\section{Total inserciones 2010}

Tabla 28

\begin{tabular}{|c|c|c|c|c|c|c|c|c|}
\hline Periódicos & Enero & Febrero & Marzo & Abril & Mayo & Junio & Julio & Agosto \\
\hline El Páis & 10 & 5 & 3 & 1 & 1 & 2 & 1 & 6 \\
\hline El Mundo & 6 & 10 & 0 & 3 & 1 & 0 & 0 & 5 \\
\hline Abc & 3 & 3 & 1 & 2 & 1 & 1 & 0 & 4 \\
\hline Público & 0 & 3 & 0 & 1 & 0 & 1 & 1 & 1 \\
\hline
\end{tabular}

Elaboración propia.

Tabla 29.

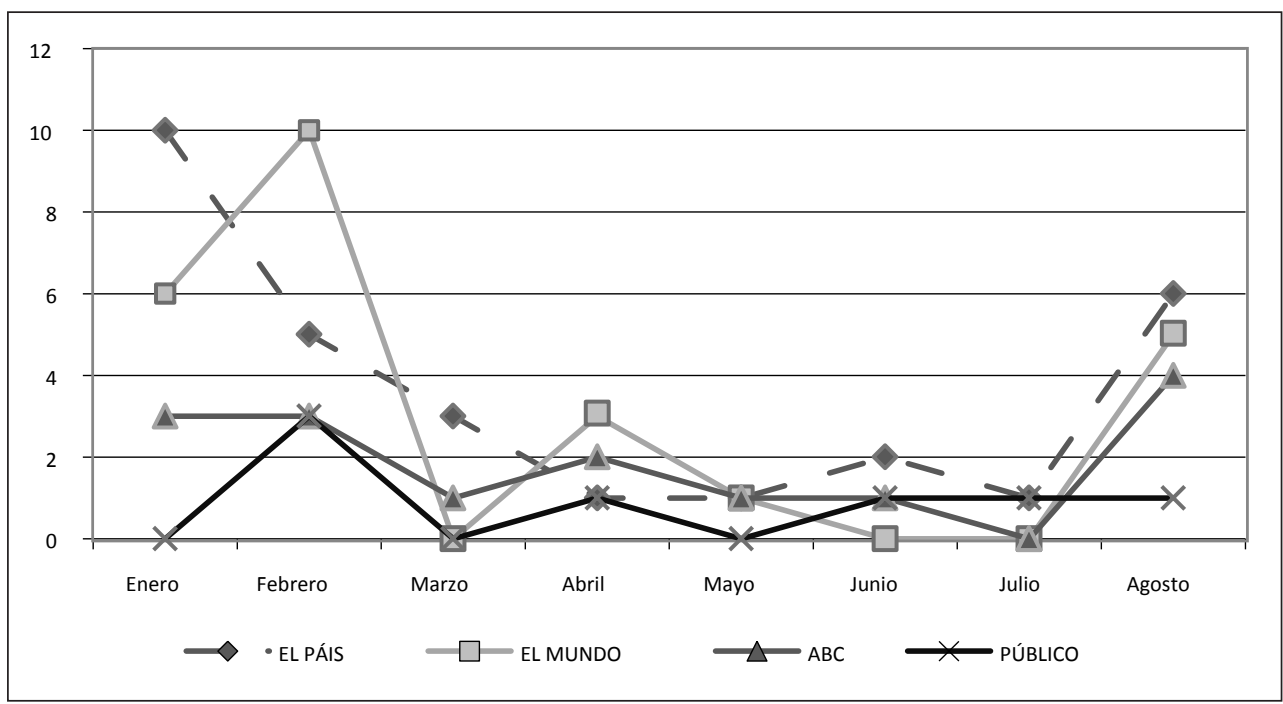

Fuente: elaboración propia

En febrero se publicó un mayor número de informaciones sobre gripe A, concretamente 21; enero contó con 19; agosto, con 16; abril, con 7; junio y marzo, con4; mayo, con 3, y julio, con 2. Por medios de comunicación, El País fue el periódico que más informaciones publicó sobre gripe A (29), seguido por El Mundo, con 25; ABC, con 15, y Público, con 7.

En este gráfico, podemos observar cómo el mayor interés informativo se dio en el mes de agosto, es decir, con la noticia de la finalización de la pandemia de Gripe A, ya que en los meses anteriores es casi anecdótico que aparezcan informaciones al respecto.

\section{Conclusiones}

Tras analizar la información obtenida, nos encontramos con que las fuentes institucionales $\mathrm{u}$ oficiales se emplean por encima del $60 \%$ en los periódicos analizados con respecto 
a cualquier otro tipo de fuente. Y, de entre ellas, la Organización Mundial de la Salud se configura como la principal fuente de información en los medios de comunicación escritos del país.

Es decir, la fuente mayoritaria estaba conformada por miembros del lobby farmacéutico -como informaron los medios de comunicación cuando anunciaron la composición del Comité de Emergencias encargado de la gestión de la pandemia- encargado de la gestión de la Gripe A, producción y venta de vacunas y también, encargado de centrar el debate, influir en las decisiones y manipular las informaciones que, posteriormente, los medios de comunicación difundirían a la población en general.

Con respecto al tipo de género periodístico empleado, observamos que los más utilizados son el informativo y el interpretativo. Concretamente, el género informativo es el más empleado por encima de un $50 \%$ en el caso de ABC, y Público, mientras que en El Mundo y El País el género interpretativo es utilizado por encima del 50\%, lo que implica que unos medios ofrecieron una visión más informativa, mientras que otros la ofrecieron más interpretativa con análisis y valoraciones no tan "objetivos".

Asimismo, durante los seis primeros meses analizados, hemos constatado que se publicaban, casi diariamente, informaciones sobre gripe A, AH1N1, gripe porcina o influenza, en los citados medios de comunicación, noticia con interés y relevancia informativa que consiguió los objetivos del lob6y farmacéutico de centrar la atención hacia el mensaje y la aceptación del mismo, y que aseguró que la interpretación fuese la pretendida, con el fin de responder a los intereses perseguidos.

Además, el mayor interés mediático se da en el período pre-pandémico (abril-mayo de 2009) y en el pandémico (junio-noviembre de ese mismo año), antes de alcanzar el periodo de menor interés informativo durante los meses de enero a julio de 2010, donde existía mucha desconfianza y críticas, por la gestión de la Gripe A que hizo la OMS.

Nuevamente, en agosto de 2010, cuando la Organización Mundial de la Salud da por finalizada la pandemia, se publica un mayor número de informaciones, y tras este anuncio nos adentramos en la era post-pandémica a partir de la cual disminuye la publicación de informaciones al respecto.

Para los intereses de la industria farmacéutica, convertirse en fuente de información institucional fue su estrategia de comunicación; así, consiguió instalar un lob6y dentro de la OMS a través del citado Comité de Emergencias, encargado de tomar decisiones de carácter vinculante para los países miembros, comité que centró la atención mediática sobre la gripe A, mediante "una campaña de comunicación con resultados sobresalientes para la industria farmacéutica".

De esta manera queda demostrado, utilizando el ejemplo sobre la comunicación del lob6y farmacéutico en el caso de la gripe A, que ante situaciones de crisis, los medios de comunicación emplean mayoritariamente fuentes de información institucionales u oficiales en la elaboración de sus noticias, que estas fuentes no son cuestionadas en su legitimidad, que la información ofrecida es difundida como legítima y digna de interés 
para la población, y que el control sobre la elaboración de esta información legitimada es deseable por parte de las organizaciones comerciales.

\section{Bibliografía}

Alterini, J. (2009). Documental Pandemia influenza Gripe Porcina/Gripe A o H1N1. Recuperado el 1 de enero de 2011 . Disponible en: http://www.youtube.com/watch?v=oAzjqJHsNNk

Calvo, Manuel. (1992). Manual de periodismo científico. Barcelona: Bosch.

Camacho Markina, Idoia (2009), "La Gripe A en la prensa española", Revista Latina de Comunicación Social. N. ${ }^{\circ}$ 64, pp.827-843. Recuperado el 19 de septiembre de 2010. Disponible en: http://www. revistalatinacs.org/09/art/865_Bilbao/66_92_Idoia_Camacho.html

Cohen, Deborah, Carter, Philips (2010). Conflicts of Interest Who and the pandemic flu", British Journal of Medicine. Recuperado el 17 de junio de 2010. Disponible en: http://www.bmj.com/content/340/bmj.c3257

Costa, Carmen. (2011). Tratamiento informativo de una crisis de salud pública: Los titulares sobre gripe A en la prensa española. N. ${ }^{\circ}$ 25. Julio. Año XIV. Páginas: 43-62. Recuperado el 4 de agosto de 2011 . Disponible en: http://www.ucm.es/info/seeci/Numeros/Numero 25/InicioN25.html

Cutlip, S, Center, A, Broom, G. (2001) Relaciones públicas eficaces. Barcelona: Ediciones Gestión, 2000.

Duncan, B. (2009). How the media reported the first days of the pandemic (H1N1) 2009. Results of EU-wide media analisis, Eurosurveillance". European communicable disease monthly, Vol. 14, N. 30. Recuperado el 1 de enero de 2010. Disponible enhttp://opac.invs.sante.fr/index.php?lvl=bulletin $\underline{\text { displayE } \mathrm{id}=2122}$

Godlee, Fiona. (2010). Conflicts of interest and pandemic flu. British Journal of Medicine. Recuperado el 3 de junio de 2010.

Disponible en: http://www.bmi.com/content/340/bmi.c2947.full

Grijelmo, Álex. (1997). El estilo del periodista. Madrid: Taurus.

Grunig, J., Hunt T. (2000). Dirección de relaciones públicas. Barcelona: Gestiones.

Hilton, S, Hunt, K "UK newspapers' representations of the 2009-10 outbreak of swine flu: one health scare not over-hyped by the Media", Journal of epidemiology and community Health. V. 65, n 10 , pp.941-946.

Krippendorf, K. (1990). Metodología de análisis de contenido. Teoría y práctica. Barcelona: Paidós.

Lippman, W. (2003). La opinión pública. Madrid: Langre.

Mccombs, M. E, Shaw, D. L. (1976). Structuring the Unseen Environment. Journal Communication Yearbook, 14, pp. 18-22.

OMS. (2005). Plan Mundial de la OMS. Preparación Influenza. Suiza: OMS.

Rogers, E, Dearing, J. (1987). Agenda setting research: Where has it been, where is it going? Communication Yearbook, 11, pp. 555-594.

Stephenson, N, Jamieson M. (2009). Securisiting Health: Australian newspaper coverage of pandemic influenza 2009". Sociol Health Illn, V. 31, N. ${ }^{\circ} 4$, pp. 525-539.

Wimmer, R., Dominick, R. (1996). La investigación científica de los medios de comunicación. Una introducción a sus métodos. Barcelona: Bosch. 